\title{
High Speed Drives Review: Machines, Converters and Applications
}

\author{
Robert Abebe, Mauro Di Nardo, David Gerada, Giovanni Lo Calzo, Luca Papini, Chris Gerada \\ Department of Electrical Engineering, University of Nottingham, Nottingham, UK \\ Giovanni.localzo@nottingham.ac.uk
}

\begin{abstract}
The development of new power electronic device and high performance magnetic materials are the main technological factors that have led both industries and research community to focus their attention on high speed electrical drives. Several papers have already outlined the electrical machine and/or converter topology choice for certain high speed application. This choice depends on the applications under study. This paper aims to identify the most important high speed applications. For each of them, the main design challenges are highlighted and an overview of available market product is presented.
\end{abstract}

Keywords—high speed, electrical machine, high speed applications, high speed drives,

\section{INTRODUCTION}

The development of new power-electronic devices, power electronic converters, manufacturing methods and materials have opened up exciting avenues in electrical machines research. One such area, high-speed electrical machines, have seen a rapid growth in the last few decades, with a considerable application uptake in the last decade. The design of high speed electrical machine is notoriously more challenging compared to classical ones, often requiring a multi-disciplinary design environment to account for the coupling between different physics aspect. The actual definition of what constitutes 'high-speed' and what is actually 'challenging design' has also long been debated in technical literature [1]-[2]. High speed machines are mainly classified according to the peripheral speed of the rotating element which translates in mechanical stresses. The main limitation in the rotational speed is therefore determined by the mechanical properties of currently available materials. However, the challenge in designing high speed electrical machine is probably best described by the ' $\mathrm{rpm} \sqrt{\mathrm{kW}}$ ' figureof-merit introduced in [1]. The growth of high speed machines is strictly connected with power electronics modules and devices which has moved towards switching modules with increased capabilities in term of switching frequencies as well as featuring a reduction in losses. The growth rate of power electronic modules has been enhanced by the introduction of wideband gap devices like $\mathrm{SiC}$ and GaN. Thanks to the introduction of high switching frequency devices, monodirectional and regenerative power converter has been adopted to actively control high speed electrical machines targeting high performance drives. The emission regulations and the cost of energy has played an important role in the industrial environment which has become more interested in direct drive solution featuring high power to weight ratio further enhancing the reliability and efficiency of the system. High speed drives has gained a growing interest in automotive, aerospace, power conversion and recovery, spindles, pump and compressors. The above application listed often requires drives which features high power and low weight in a limited volume. Increasing the rotational speed enables the reduction of the overall volume while through optimized design high power density can be achieved. However, high speed drives has also become state of the art for some of the aforementioned application while in some niche application, the adopting of high speed drives has enhanced the performances and the capabilities in terms of system efficiency, product quality and product innovation.

TABLE I: POWER-SPEED NODES FOR SELECTED APPLICATIONS

\begin{tabular}{c|c|c} 
Application & Power & Speed \\
\hline Oil \& Gas & $3 M W$ to $15 \mathrm{MW}$ & $5-15 \mathrm{krpm}$ \\
\hline Spindles & $300 \mathrm{~W}$ to $60 \mathrm{~kW}$ & $15-300 \mathrm{krpm}$ \\
\hline $\begin{array}{c}\text { Turbocharger } \\
\text { (Pass-car } / \text { Truck) }\end{array}$ & $1-3 \mathrm{~kW} / 10 \mathrm{~kW}$ & $\begin{array}{c}150 \mathrm{krpm} / \\
80 \mathrm{krpm}\end{array}$ \\
\hline Air Compressor & $40 \mathrm{~kW}$ to $500 \mathrm{~kW}$ & $15-80 \mathrm{krpm}$ \\
\hline $\begin{array}{c}\text { Micro-turbines } \\
\text { Turbo-molecular } \\
\text { pumps }\end{array}$ & $30 \mathrm{~kW}$ to $400 \mathrm{~kW}$, & $15-120 \mathrm{krpm}$ \\
\hline
\end{tabular}

Different topologies have been adopted for what concerns the electrical machines. Considering the challenges in achieving high speed, the robustness of the rotating element is a critical factor in the selection and design of the machine. New materials, improved power electronic devices and the engineered integration process at the design stage are improving the capabilities of high speed drives in the industrial market [1]. In the following sections, the authors present a review on the application of high speed technology and their role in the industrial environment. Table I summarizes the key industrial application focusing on their power-speed mode of operation. The machine topologies mainly adopted as well as the power electronics implemented is described focusing on their key aspects to achieve high operational speed. 


\section{OIL AND GAS APPLICATIONS}

Gas compression is needed at many places in the chemical, oil and gas industry, mainly for gathering, transmission and processing the gas downstream. Gas engines and gas turbines are traditionally used as the compressor drives. While gas fired drives are convenient for gas companies, they are becoming increasingly difficult to install due to environmental restrictions. The idea of using electric motors to drive compressors to minimize the environmental, regulatory and maintenance issues is not new, but progress in the field of high speed machines have made them more attractive. Oil free compressors have been successfully used for many years but as long as a lubrication system for the oil is still necessary for the drive, or for a gearbox, the benefits of oil-free operation cannot be fully exploited. Electric high speed drives with magnetic bearings allow the elimination of the gearbox and of the entire lubrication oil system, which leads to increased safety, efficiency and availability as well as reduced operation and maintenance costs. Thus, the electric high speed drives are the most environmental friendly compressor drives.
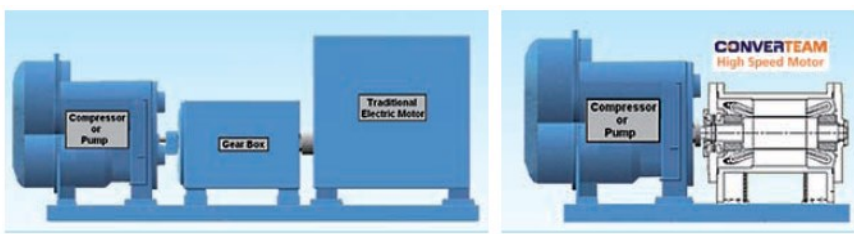

Fig. 1. Conventional Compressor (left) and Integrated Compressor (right)

This market is widely dominated by Induction Machines in the $3 \mathrm{MW}$ to $15 \mathrm{MW}$ range, with corresponding speeds in the range of $5 \mathrm{krpm}$ to $20 \mathrm{krpm} \mathrm{[3].} \mathrm{Traditionally,} \mathrm{solid} \mathrm{rotor}$ machines were considered the most appropriate technology due to the required high power-speed product [4]. The solid rotor structure is characterized by low manufacturing cost and robust rotor structure which enables to increase the operative peripheral speed of the machine although requiring accurate and strongly linked multi-physics design process. Solid Rotor induction machines are very attractive for application in aggressive environment which implies high operative temperatures and corrosive gas. With special rotor features and high strength electrical steel, the Laminated Rotor Induction Machine is also becoming increasingly used in this market [5].
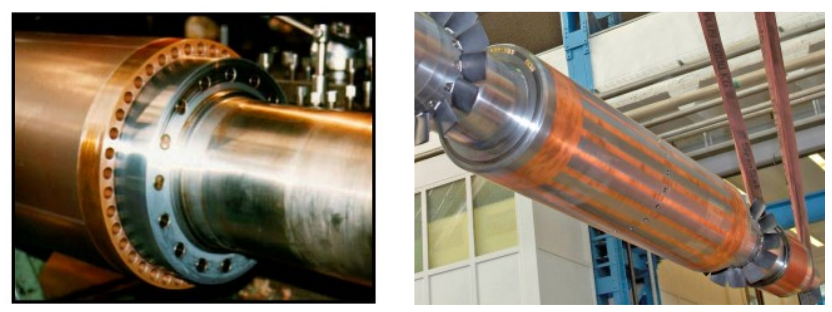

Fig. 2. High speed laminated rotor IM left [GE Energy] and solid rotor IM right [Siemens Yaskawa] used within an integrated compressor unit
The layout and rotor of a laminated rotor Induction Machine from GE and a solid rotor Induction Machine from Siemens Yaskawa, used for Oil-Gas applications are shown in Fig.2. While PM machines are technically capable of achieving some of the power-speed products for this market, their use is largely disadvantaged by the amount of magnet required and associated cost and assembly issues due to the relatively big dimensions of such rotors.

Market players: Siemens-Yaskawa (solid rotor IM), MAN (solid rotor IM), Sundyne (solid rotor IM), GE Power Conversion (laminated rotor IM), Toshiba-Mitsubishi (laminated rotor IM)

\section{Drives:}

Concerning the power electronics, due to the higher powers used for this application, higher voltages in the range $3 \mathrm{kV}$ $8 \mathrm{kV}$ are used to limit the current. Typical architectures include a high pulse $(24,36)$ diode converter rectifier for low harmonic distortion at the input stage. Multi-level inverters with 4 or 5 stages are used to produce a motor-friendly waveform, with output frequencies up to $250 \mathrm{~Hz}$. For the high voltages and currents handled devices such IGBTs, IEGTs (Injection Enhanced Insulated Gate) and GCTs (Gate Commutated Thyristors) are used for the inverter stages [6]. Fig.3. shows typical devices used within such drives produced by Toshiba-Mistubishi. Challenges remain in relation to power density - state of the art converters are about three to five times the size of the machines. For the future $10 \mathrm{kV}+\mathrm{SiC}$ devices will allow more compact, efficient, two-level high speed drives [7].
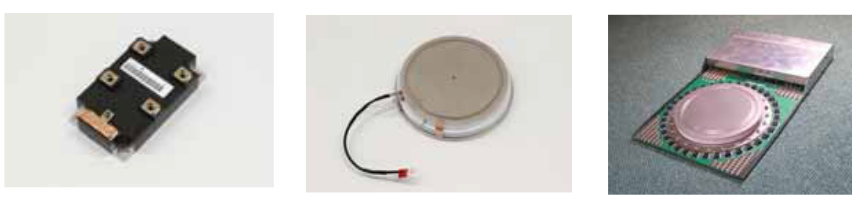

Fig. 3. IGBT $(4.5 \mathrm{kV}, 900 \mathrm{~A})$ left, IEGT(4.5kV,2.1kA) centre, GCT $(6 \mathrm{kV}$, $6 \mathrm{kA}$ ) right [Toshiba-Mistubishi]

\section{AIR COMPRESSORS}

Air compressors account for one of the fastest growing markets for high speed motors in industry and typically consume over $15 \%$ electricity requirement. Until recently, air compressors and blowers have utilised Induction motors due to its renowned ruggedness and low cost. However, the clamour for high speed motors with particular emphasis on high power density and efficiency has seen a shift from Induction motors to permanent magnet ones. Specialised environments where contamination risks should be minimised (like food and beverage industries, pharmaceutical industries and high quality painting industries), form the main market for air compressors and blowers. This has seen a gradual shift to demand for high speed, high power, and oil-less air compressors as opposed to the traditional oil-lubricated compressors. 


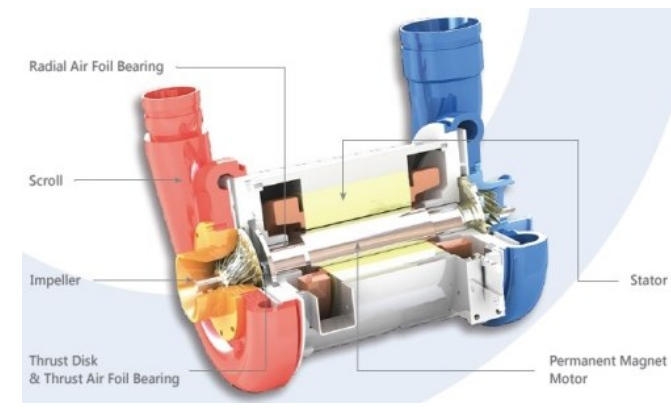

Fig. 4: Surface PM Machine used within an Industrial Air Compressor [K-turbo]

Direct drive PM motors offer high power density and efficiencies whilst avoiding the potential risks associated with oiled gearboxes and mechanical bearings in induction motors. Figure 4 shows an example of PM air compressor used in industry [8]. The small size requirements for air compressors and blowers also point to PM motors as the choice motors in industry.

Market players: K-Turbos (Surface-PM, up to $400 \mathrm{~kW}$ $65 \mathrm{krpm}$ ), SKF (Surface-PM, up to $150 \mathrm{~kW} 60 \mathrm{krpm}, 300 \mathrm{~kW}$ 30krpm, 70kW 30krpm), Suzler (Surface-PM, 50krpm), Corac (Surface-PM, 150kW 45krpm), CompAir (laminated rotor IM, $300 \mathrm{~kW} 60 \mathrm{krpm}$ ), Switch-Yaskawa (solid rotor IM, $300 \mathrm{~kW} 12 \mathrm{krpm}$ ) and Sundyne (solid rotor IM, 300kW $60 \mathrm{krpm})$.

Although PM motors are more prominent in air compressor and blower applications, some manufacturers use laminated as well as solid rotor Induction Machine technology for this market especially for the higher power ratings.

Drives:

The drive portfolio for compressor applications is quite diverse, especially with respect to available power electronics topologies. In fact, based on the specific application either conventional 2-Level full-bridge IGBT converters or 3-Level NPC converters using IGBTs or GTOs are used. For higher power levels, cascaded 3-Level NPC converters are used to obtain output voltage waveforms with 9 to 17 levels.

\section{SPINDLES}

Conventional low cost, high speed spindles have been historically implemented with belt drives configurations, which features limitations in the maximum speed achievable. In these applications, high speeds are necessary to guarantee high volumetric material removal rates, therefore spindles applications have traditionally driven and pushed the research community and industry towards high speed direct drive solutions. Spindle applications can be mainly divided in three areas - milling, grinding and drilling. The maximum rotational speed needed during each of this operation depends on the material under process. Therefore the power range and speed limits in spindle applications are very wide, going from 6 krpm up to $300 \mathrm{krpm}$, with a power approximately from 200 $\mathrm{W}$ to $24 \mathrm{~kW}$ [9]. Among the new applications that require very high speed spindles, it is worth mentioning the ever increasing speed (up to 1 million rpm) needed for printed-circuit-board
(PCB) drilling and dental surgery tools (up to $40 \mathrm{krpm}$, with power ratings of 10-20 W). The latter has been traditionally implemented through air turbines fed by compressed air; therefore each tool operates at a single speed requiring several tools with different speeds. By replacing the traditional air turbine tools with electrical drives could reduce the number of tools and add the benefit of having an accurate speed and torque control [10]. Spindle motors typically operate in nonaggressive thermal environments and the main design constraints are high power density, low vibration limit, high dynamic stiffness and the possibility of withstand high axial loads. Most spindle applications require a wide constant power-speed range therefore this market is dominated by IMs. For higher powers, lower rotational speeds laminated constructions are used, while for the highest rotational speeds (up to $300 \mathrm{krpm}$ ) copper-coated solid rotor induction machines are typically used (Fig 5) [11]. Due to increasing demands on efficiency and power-density, surface PM are also finding a share of this market especially where the required constant power-speed range is smaller.

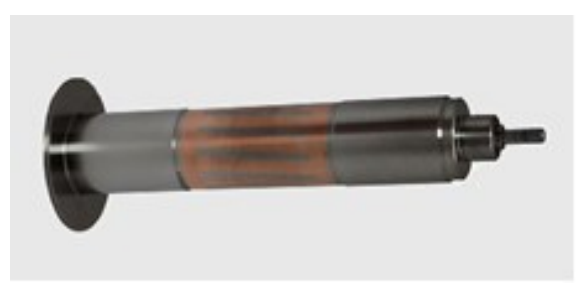

Fig 5: Caged solid rotor IM used within high-speed PCB drilling spindle [Westwind]

Market players: Mistubishi Electric (laminated IM, 30kW $25 \mathrm{krpm}, 22 \mathrm{~kW} 30 \mathrm{krpm}, 7.5 \mathrm{~kW} 60 \mathrm{krpm} ; \mathrm{IPM} 7.5 \mathrm{~kW} 60 \mathrm{krpm}$ ), Air-Bearings Ltd. (solid IM 330W 350krpm, SPM 1.2kW $80 \mathrm{krpm}$ ), Servax (laminated IM 60kW 27krpm, SPM 53kW 30krpm), Siemens (IM and SPM $18.5 \mathrm{~kW} 24 \mathrm{krpm}$ ).

\section{ELECTRICALLY ASSISTED TURBOCHARGERS}

The concept of placing an electrical machine between the turbine and the compressor wheel (Fig. 6) in a turbocharger is not new.

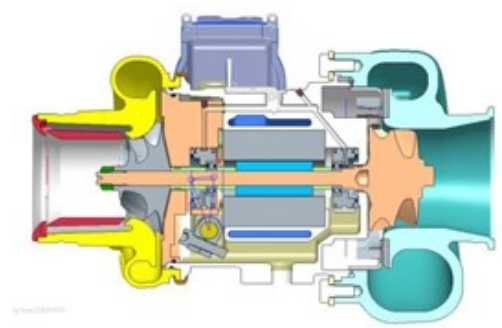

Fig. 6: EAT with electrical machine placed between turbine and compressor [Cummins]

In such configuration, the machine can be used as a motor on starting and gear-shift, thus reducing turbo-lag and improving drivability, and as a generator on high engine loads, when there is excess energy in the exhaust gases hence improving efficiencies. It is well-known that the integration of high speed electrical machines within such an aggressive environment is technically challenging, taking into account 
the high exhaust gas temperatures (in excess of $800^{\circ} \mathrm{C}$ ) on engine shutdown. Another typical design constraint imposed by this application is the constant power requirement of the machine over a wide speed range.

A number of projects targeting this application have been described in literature. A comprehensive multi-domain topology selection studies for this application is presented in [12] in which the authors compare the suitability of laminated-rotor Induction Machines, distributed-wound surface PM Machine and concentrated-wound surface PM Machines for a $20 \mathrm{~kW}$ node. The distributed-wound PM Machine achieves the highest design-point efficiencies and lowest rotor temperatures, but its application is hindered by the necessity to oversize the converter due to the limited fieldweakening capability. Conversely, the concentrated-wound PM Machine, having high a high inductance, achieves the required constant-power speed range. However, due to the high armature MMF harmonics, the magnet losses are high, even after multiple segmentations. The high magnet losses, compounded with the application's high temperatures make the rotor temperature prohibitively high. The laminated rotor induction machine is arguably the best overall candidate since it naturally field weakens, and through a design technique involving the reduction of rotor losses [2] the rotor temperature can be controlled to safe limits. An alternative to the Induction Machine for this application is presented by Mitsubishi Heavy Industries (MHI), where a concentratedwound PM Machine with an unusual slot-pole combination is used, [13]. This combination achieves the field-weakening requirement and low rotor-losses at the cost of a low-winding factor (0.5) and higher stator copper losses, which are easier to dissipate due to the proximity to the cooling jacket. As previously explained the main design challenge of the electrically assisted turbocharger is the huge axial temperature gradient that the electrical machine has to withstand. Two interesting approaches have been implemented in order to avoid such aggressive environment. The first one involves placing the electrical machine in front of the compressor wheel (i.e. much less thermally aggressive); however this solution needs an additional bearing to support the machine. In the second approach the turbine wheel and compressor wheel are mechanically decoupled and each connected to a separate high-speed electrical machine [14]. It is often referred to as a "Fully Electric Turbocharger". By having such a decoupled configuration the turbine wheel and compressor wheel can run independently and at different speeds enabling the performance of each to be optimized. It also delivers enhanced performance and higher efficiency, with the disadvantage of increasing the hardware costs.

Market Players: Cummins (IM inboard, PM outboard $20 \mathrm{~kW} 120 \mathrm{krpm})$, Garrett (IM), Ecomotors (IM), Satcon (IM), MHI (PM 2kW220krpm), G+L (PM outboard $1.5 \mathrm{~kW}$ $160 \mathrm{krpm})$, Aeristech (Surface PM).

\section{MICRO-TURBINES}

A micro-turbine is a small, single-shaft gas turbine integrated with high speed electric generator (up to $120 \mathrm{krpm}$ ). The typical rated power ranges from 30 to $400 \mathrm{~kW}$ even though recently micro-turbines with power ratings up to $1 \mathrm{MW}$ have emerged on the market. They are typically used for stationary generation applications at sites with space limitation for power production and can run on a variety of fuels. Micro-turbines usually operate in a narrow speed range and since a high power density is required, surface-mount PM machines are predominantly used, as shown in Fig. 7 which shows PM Machines produced by Capstone and Ansaldo, Fig $7 \mathrm{a}$ and $\mathrm{b}$ respectively.

Market Players: Capstone (Surface PM) 30kW 120krpm, Ansaldo (Surface PM) 100kW 70krpm.

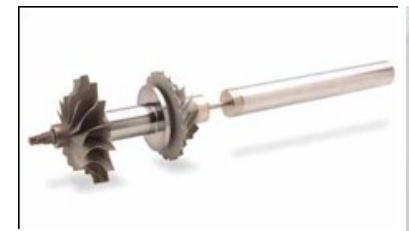

a)

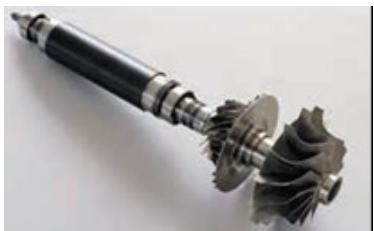

b)
Fig.7: Microturbine SPM rotors: a) [Capstone], b) [Ansaldo]

\section{TURBOMOLECULAR PUMPS}

Turbomolecular pumps (as depicted in Fig. 8) have a similar design to turbines and are used to obtain and maintain a high vacuum.

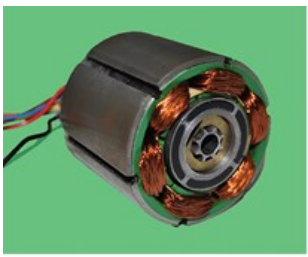

Fig. 8: High speed SPM used within turbomolecular pump [BEI Kimco]

The vacuum environment created by a turbomolecular pump (TMP) is essential in manufacturing processes of semiconductors, dye chemical, plastics and solar cells. This requires motors that can provide very high speeds (up to 90 $\mathrm{krpm}$ ) at relatively low power ratings. A complex design approach (especially of the rotor) of the motor is required to accommodate the load demands typical in TMP applications. The operation of a TMP sees its rotor subjected to very high speeds in deep vacuum posing potential thermal exchange problems [12]. These thermal exchange problems are as a result of heat dissipation restricted to only radiation due to the vacuum state. The high speeds in the TMP also lead to friction heat build-up, further imposing design limitations. Magnetic and/or ceramic shaft bearings are used to reduce friction and oil contamination. However, the cost of these high grade materials is a drawback. The high speeds and low power ratings of the pump sees the market dominated with PM Brushless DC motors as the choice motors for TMPs. The choice of PM machines has become very prominent due to manufacturers offering magnetically levitated shaft bearings which are either permanent magnets for small sized pumps or a combination of dynamic and permanent magnetic fields, for shaft support without contact. These turbo pumps offer bearings that never wear down and a true zero oil-vapour back streaming. Turbo molecular pumps utilising induction 
machines also exist in industry especially for lower speed application.

Market players: Edwards Vacuum (surface PM, $90 \mathrm{krpm}$ ), Pfeiffer Vacuum (surface PM, $90 \mathrm{krpm}$ ) and Osaka Vacuum (surface PM, $80 \mathrm{krpm}$ ).

Drives:

Power electronics converters for turbomolecular pumps are often built around the specific machine structure and tailored for the specific application. The conventional voltage and current ratings renders MOSFETs the primary used technology, as well as 2-Level full-bridges as the choice topology (turbomolecular pumps share some likeness with spindle drives in terms of speed and power ranges).

\section{FUTURE TRENDS}

Oil and gas compressors - Induction motors look to remain the machine choice in this sector for the foreseeable future. This is due to its robustness, high power rating capability and more importantly low cost. Advancements in power electronics research - especially wide band gap devices will allow for more efficient drives with an overall smaller volume compared to current commercially available options enabling increasing power density as well as efficiency.

Air compressors - PM machines are currently phasing out IMs in this sector and the former is expected to dominate in future. With the market strongly dictating the direction of advancement in this sector, a more Integrated Motor Drive (IMD) solution is expected in the future - with the converter closely physically integrated in the machine housing. This is due to the small overall volume requirement of air compressors. The diverse portfolio of converter topologies compatible with the air compressors also allows for its seamless integration for and IMD solution.

Spindles - IMs look to continue to dominate the market in this sector and PMs are unlikely to overtop it anytime soon. The vibration and high power density concerns stemming from close coupled integration of the drive and the high speed motor will be alleviated in future with ongoing research on more robust power electronics options.

Microturbines - The spatial constraints and high power density requirements mean PM machines will continue to dominate this sector in the future.

Turbomolecular pumps - PM machines will continue to dominate the market share in this sector due to the demand for an oil-free environment to reduce contamination and reduced maintenance cost due to long lasting shaft bearings not damaged from friction wear. SiC MOSET devices look to be heavily used in the future to meet and exceed both power and mechanical requirements.

As a general trend, innovative material and manufacturing techniques on the electrical machine side as well as the development of high performance and more compact power electronic modules will enables further development of high efficiency high speed drives. IMD and a full multiphysics design of the drive system could possibly held to innovative solutions where the key features of both electrical machines and power electronics are enhanced each other.

\section{CONCLUSION}

This paper has attempted to give an overview on the main design challenges related to the design of high speed electrical machines for the most important applications. In Fig. 9, the main high speed drives considered have been collected in a double logarithmic chart. Each application is mainly concentrated on different power-speed ranges. The high speed challenge in the industrial environment is nowadays limited to $10^{\wedge} 6 \mathrm{rpm} \sqrt{ } \mathrm{kW}$. In particular is possible to highlight that Oil \& Gas application exploit the high power-lower speed range while turbocharges and turbo compounding application challenge the high speed-lower power range. The harsh operative environment of such applications, push the technology to more simple and robust structure which enhance the benefit for high peripheral speed operation of the electrical machines and further increase in both ' $\mathrm{rpm} \sqrt{\mathrm{kW}}$ ' and power density is expected. The midpower range is exploited by vacuum pump, spindles and compressor which are developed for a wide range of speed according to the application specification. The high speed drives are gathering importance on the generation and propulsion system in vehicular application, possibly introducing innovative solutions to push the boundaries detailed in this work.

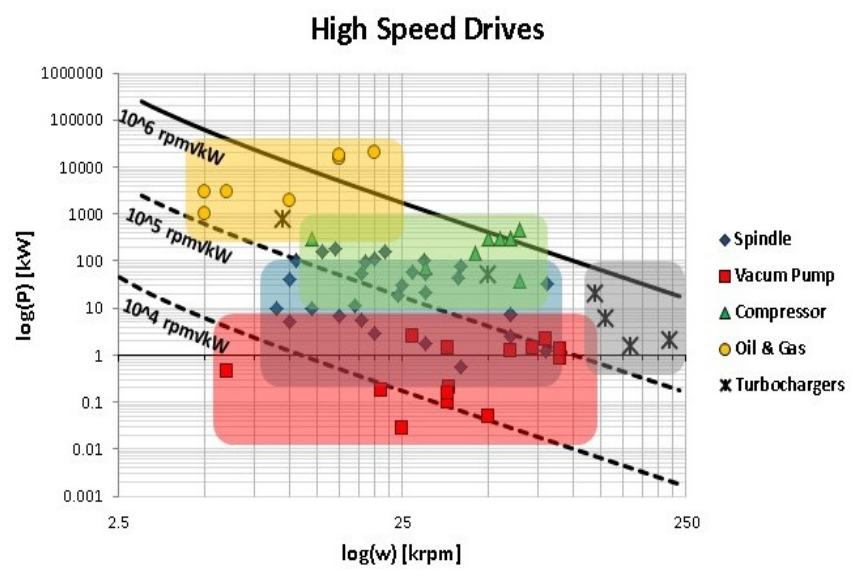

Fig. 9: High speed drives summary

\section{REFERENCES}

[1] D. Gerada, A. Mebarki, N. L. Brown, C. Gerada, A. Cavagnino, and A. Boglietti, "High-Speed Electrical Machines: Technologies, Trends, and Developments," IEEE Transactions on Industrial Electronics, vol. 61, pp. 29462959, 2014.

[2] M. A. Rahman, A. Chiba and T. Fukao, "Super high speed electrical machines - summary," Power Engineering Society General Meeting, 2004. IEEE, Denver, CO, 2004, pp. 12721275 Vol.2. 
[3] M. A. Rahman, A. Chiba and T. Fukao, "Super high speed electrical machines - summary," Power Engineering Society General Meeting, 2004. IEEE, Denver, CO, 2004, pp. 12721275 Vol.2.

[4] L. Papini, C. Gerada, D. Gerada and A. Mebarki, "High speed solid rotor induction machine: Analysis and performances," Electrical Machines and Systems (ICEMS), 2014 17th International Conference on, Hangzhou, 2014, pp. 2759-2765.

[5] R. Lateb, J. Enon and L. Durantay, "High speed, high power electrical induction motor technologies for integrated compressors," Electrical Machines and Systems, 2009. ICEMS 2009. International Conference on, Tokyo, 2009, pp. $1-5$.

[6] S. Singhal, H. Walter and T. Tyer, "Concept, design and testing of a 12MW 9500 RPM induction motor with oil film bearings for pipeline applications in North America," Industry Applications Society 60th Annual Petroleum and Chemical Industry Conference, Chicago, IL, 2013, pp. 1-16.

[7] K. Weeber, (2014, Sept). Motor Drives for Oil and Gas Potential application areas and benefits of SiC. GE Global Research. [Online].Available: http://www.nist.gov/pml/high megawatt/upload/RajuAPPROVED.pdf

[8] http://www.turbo-k.com/

[9] A. Boglietti, A. Cavagnino, A. Tenconi and S. Vaschetto, "Key design aspects of electrical machines for high-speed spindle applications," IECON 2010 - 36th Annual Conference on IEEE Industrial Electronics Society, Glendale, AZ, 2010, pp. 1735-1740.

[10] C. Zwyssig, M. Duerr, D. Hassler and J. W. Kolar, "An Ultra-High-Speed, $500000 \mathrm{rpm}, 1 \mathrm{~kW}$ Electrical Drive System," Power Conversion Conference - Nagoya, 2007. PCC '07, Nagoya, 2007, pp. 1577-1583.

[11] J. F. Gieras and J. Saari, "Performance calculation for a high speed solid-rotor induction motor," IECON 2010 - 36th Annual Conference on IEEE Industrial Electronics Society, Glendale, AZ, 2010, pp. 1748-1753.

[12] T. Ishikawa, Y. Hashimoto, and N. Kurita, "Optimum Design of a Switched Reluctance Motor Fed by Asymmetric Bridge Converter Using Experimental Design Method," IEEE Transactions on Magnetics, vol. 50, pp. 781-784, 2014.

[13] D. Gerada, D. Borg-Bartolo, A. Mebarki, C. Micallef, N. L. Brown, and C. Gerada, "Electrical machines for high speed applications with a wide constant-power region requirement," in Electrical Machines and Systems (ICEMS), 2011 International Conference on, 2011, pp. 1-6.

[14] T. Noguchi, Y. Takata, Y. Yamashita, Y. Komatsu, and S. Ibaraki, "220000 r/min 2kW PM Motor Drive for Turocharger," IEEJ Trans. Industry Applications, vol. 125, pp. 854-861, 2005.

[15] K. Shiraishi and Y. Ono, "Hybird Turbocharger with Integrated High Speed Motor-Generator," Mitsubishi Heavy Industries, vol. 44, 2007. 